\title{
The future of individualization in Europe: changing configurations in employment and governance
}

\author{
Nikolai Genov \\ Received: 19 August 2014 / Accepted: 29 October 2014 / Published online: 20 November 2014 \\ (C) The Author(s) 2014. This article is published with open access at Springerlink.com
}

\begin{abstract}
The accelerated individualization brings immense promises for innovations in technological development, for improvement of the economic and political organization and for creativity in the cultural life of European societies. The expected changes will most probably liberate individuals from constraints in their personal development and realization. Simultaneously, individualization brings about new complexities, uncertainties and controversies. Some of them are relatively easy to manage, given the proper understanding of the challenges and the efficient coping with them. Other uncertainties and controversies are difficult to handle today and bear the potentials of future clashes at various structural levels. The major reason for tensions, conflicts and clashes is rooted in the scarcity of resources. They are never sufficient to fully satisfy the aspirations for individualization of particular individuals or groups of individuals. The current conditions, manifestations, effects and prospects of the global trend of individualization are analyzed in the contexts of employment and governance in Europe.
\end{abstract}

Keywords Individualization · Employment · Governance · Europe

\section{Introduction}

In the sixties of the XXth century, futures studies regularly envisaged foreseeable enlargements of the social space for individuals' activity. The typical example was the prediction

This article is part of the Topical Collection on The Future of Europe, guest-edited by Markus Pausch

N. Genov $(\bowtie)$

School of Advanced Social Studies, Gregorciceva 19, 5000 Nova

Gorica, Slovenia

e-mail: nikolai.genov@fuds.si of mass private use of helicopters. They were seen as competitors to cars in offering individualized transportation services in the very near future. This forecasting went wrong, but a lot of others stressing the rise of opportunities for autonomous choice and action of individuals came true or are still to be materialized soon. In the meantime, recent political processes changed the angle of the forecasting about the future of the autonomous orientation, decision and action of individuals. Defined as "individual empowering", individualization has recently been identified as the major global trend in the time perspective till 2030. The next in the same ranking are the global trends of the diffusion of power, the changing demographic patterns and the food, water and energy nexus [29]. This is an impressive signal for the need to discuss the European future of the global trend of individualization in detail. Its prospects will be decided in the fierce competition for successful active adaptation to global trends. This will happen under the conditions of interconnected local and global processes and in the frame of the global time-and-space compression.

The active local adaptation to the global individualization is expected to reach both the structural and the action dimensions of the trend. Its structural dimension manifests itself in differentiations and enlargements of social spaces available for the autonomous activity of individuals. The changing social spaces allotted to individuals in the progressing technological and economic division of labour are typical examples for the structural characteristics of individualization. The action dimension concerns the increase of the capacities of individuals to autonomously and efficiently orient themselves, make decisions and act. This typically happens on the basis of the rising educational level and due to the acquisition of new skills by individuals. The human conditions of the present-day individualization are inherently linked to the evolution of biological and social abilities of individuals to acquire, accumulate, improve, transmit knowledge and skills and 
intentionally apply them in mental and practical activities [ 15 , 16]. Therefore, the discussions on the future of individualization in Europe have to take into account evolutionary advancements, continuities and interruptions in the manifestations of the global trend.

Individualization is at work in all action spheres and at all structural levels of sociality - from the face-to-face interactions in localities to the structural level of the world society. Successful activity in the area of research is impossible without the motivation of talented individuals to bring about breakthroughs in knowledge. Technological and economic development is unimaginable without the inventiveness, dedication and endurance of innovators. The differentiation and enlargement of social spaces for autonomous orientation, decision and action of individuals repeatedly comes about as a result of their taking part or even their self-sacrifice in political struggles. Individuals are the creators and mediators in the spread of cultural innovations. In the constructive scenario, the attempts of national and multinational organizations, of societies and supranational associations at mobilizing individuals for their own organizational goals foster individualization. In return, individualization supports the rationalization of organizations. The destructive scenario includes hindrances put by organizations in the way of individualization. The boomerang effect is the undermining of the efficiency of organizations or their demise due to the negatively affected human capital of the organizations in the long run.

The impressive manifestations of individualization in the present day predominantly urbanized world and mostly in the economically advanced societies of Europe and North America [17, 3, 4, 22, 2, 6, 10] have deep historical roots. The division of labour started in the primitive societies and progressed with fluctuations throughout human history. The related individualization was nowhere evolutionarily unilinear. There were repeated cases of disruption of individualization due to natural disasters, wars, migrations or dictatorships. In the pre-modern societies, individualization was possible for small elites as a rule. The trend impressively unfolded and flourished with global implications in Europe in the course of and after the Reformation, the Enlightenment and the continental industrial revolution. The mutual influence of these three processes brought about the unique European focus on the moral and social value of the individual and his/her roles in the reproduction and change of society [31]. Europe became the birthplace of a civilizational model with the individual's economic, political, social and cultural rights in the centre of the model. Its development was intrinsically linked with the emancipation of the individual from economic and political oppression and with the secularization from restrictive cultural traditions. In the course of modernization, this model spread all over the world with particularly strong manifestations in
North America [28]. The major forces supporting global individualization are the worldwide markets, the global transportation and communication as well as the development of a global culture.

The future of individualization in Europe is being largely decided today. The effects of individualization which will become manifest tomorrow are being accumulated in the present-day competition and cooperation between individuals, business companies, states and supranational organizations. The contemporary high dynamics of individualization in Europe have brought about mostly constructive success stories. Due to technological, economic, political and cultural changes in the recent continental history, the average individuals in the affluent European societies ${ }^{1}$ enjoy a very wide range of options for choice among areas, directions and modalities of action. In the area of work, a large variety of occupational choices is open for selection and realization to millions of Europeans. The democratic political participation is everyday reality for millions of them as well. A plethora of educational paths and plenty of cultural activities are on the agenda of human activities on the continent. The fast rise of the level of general and specialized education has enriched the Europeans with cognitive capacities and practical skills to efficiently handle complex and complicated tasks. Under these conditions, the making of personal biographies is more and more often a matter of personal preferences and design. Personal development is to a large extent free from the pressure of economic and political circumstances as well as from restrictive family relations or cultural traditions.

The studies on individualization in the advanced European societies have discovered and analyzed numerous success stories but shady sides of the process as well. The fast rise of options and resources for individual development and realization meets constraints due to the fact that the new opportunities for autonomous orientation, decision and action are inherently linked to new requirements for the competent and efficient handling of growing numbers of complicated tasks and responsibilities. Not everybody is capable of keeping the pace with the changes and with the new requirements for an efficient performance in task management. Thus, the global trend of individualization has in-built internal contradictions causing psychological and social frictions, tensions and conflicts [21]. The technological, economic, political and cultural resources available for individual action are generally scarce and will remain so. The competition for access to resources is getting more intensive and the risks of personal failure in the management of tasks are and will be omnipresent. The mechanisms of imposing structural discipline and punishment for improper or inefficient action of individuals (Foucault) remain high on the agenda of action. Under widespread affluence,

\footnotetext{
${ }^{1}$ According to the UNDP, 31 out of 49 countries with very high human development index worldwide are European countries [4: 1641].
} 
millions of human beings in Europe - mostly in Eastern Europe and immigrants in the Western part of the continent - still struggle for the basics of human existence. For them, the plethora of options for personal development and realization remain difficult to attain [38: 101f.]. The progress in the area notwithstanding, gender inequalities are still a matter of everyday experience in Europe.

The brief diagnosis of the present-day achievements and problems of individualization in Europe leads to the conclusion that the large variety of future opportunities for development and realization of Europeans is full of promising prospects, potential contradictions and manifest conflicts. The exclusive emphasis on the expansion of rights and freedoms of individuals made public by disregarding or underrating the concomitant rise of individual responsibilities brings about social pathologies. They undermine solidarity as the glue of social life. Thus, individualization tends to come about in the "late" European modernity at the expense of various forms of common good in general, and of various forms of solidarity in particular [5: 71-94, 36]. Individualization is not just a blessing but might be also a curse for individuals or groups of individuals. As seen from another angle, individualization is simultaneously an ideal and a practical goal in everyday life. In certain circumstances, real struggle is needed in order to attain this desirable goal.

The currently accelerated individualization brings immense promises for innovations in technological development, for improvement of the economic and political organization and for creativity in the cultural life of European societies as well as in the global society. The expected changes will most probably liberate individuals from many current constraints in their personal development and realization. Simultaneously, individualization brings about new complexities, uncertainties and controversies. Some of them are relatively easy to manage, given the proper understanding of the challenges and the efficient coping with them. Other uncertainties and controversies are difficult to handle today and bear the potentials of future clashes at various structural levels. The major reason for tensions, conflicts and clashes is rooted in the scarcity of resources. They are never sufficient to fully satisfy the aspirations for individualization of particular individuals or groups of individuals.

The future of individualization in Europe deserves special attention concerning the area of work and concerning the issues of governance at various structural levels.

\section{Changing patterns of individualization in employment}

Only until recently, the options for individualization were mostly identified in the area of choice and decisions concerning the life trajectory and in the management of leisure time. The area of work - traditionally understood as dependent employment - has rarely been discussed from this angle. The situation has changed and a lot of changes in the future can be foreseen. The employed, self-employed, semiindependent and free-lance ICT practitioners or high-level managers already enjoy substantial autonomy in designing the agenda of their working time. This is an achievement which will be followed by other occupational groups involved in project organization of work. It offers many opportunities for individualization. In addition, the members of the privileged occupational groups are able to plan and enact the connection between work and working time, on the one side, and leisure and family life, on the other, more and more autonomously. This is a trend which will change the planning and action of larger and larger groups of working individuals in the future [32].

Just before the recent global financial and economic crisis, analysts at Gartner Inc. published a future study under the provocative title "Future Worker 2015: Extreme Individualization". The basic assumption of the forecasting was breath-taking: "Future Worker 2015 will be the intellectual driver of successful companies, empowered by individualized tools, knowledge, information sources, social networks and employment styles" [27, 1]. Having experienced the national and global decline of the GDP after 2008, the rise of unemployment, the sovereign debt crisis in the Eurozone and the struggle of companies, states and the European Union to manage the challenges, Europeans cannot be so optimistic now. Moreover, the European analysts tend to question the assumptions about the reflexive worker who would be able and willing to take the responsibilities of purposeful individualization [2]. Nevertheless, the vision by Morello and Burton could be used as a general orientation about what is already happening in the European working life, although much slower than expected. The realistic approach to the process requires a multidimensional analysis. First, changes in the organization of work and in the action patterns of employees should be taken into account. Second, the analysis has to include also the changing conditions of decision-making and coordination at national and European (EU) level.

The developmental strategy of the European Union is currently guided by the idea of re-industrialization [42]. The idea is very timely, given the challenge of the third industrial revolution [33] and the rise of the Chinese economy. It managed to become the new Manchester of the world in only several decades. The Chinese industrial expansion made clear the negative effects of the deindustrialization of European and North American societies. The core of the European strategy of re-industrialization is the rapid development and intensive use of new digital technologies in production and services. These new technologies are mostly the symbiosis of computing and telecommunications, of cloud computing and big data processing. The result is expected to be the full-scale digitalization of the industrial production lines and services in 
Europe. This effect is already achieved in the economy of scale of mass car production. However, the full-scale digitalization is still the future task in the manufacturing of "tailored" products with the highest value-added. These products are individualized according to the requirements of the clients. The economically efficient individualization of industrial products becomes possible due to the high level of digitalization of design and production [25].

What are and will be the implications of this new technological development on individualization? The winners in the process are and will be the groups consisting of ICT professionals in the local European labour markets. These professionals are well connected to the global labour market by the outsourcing of production lines and services. High-quality jobs will continue to be offered to the ICT specialists who are scarce in the European labour market today. The demand for additional ICT practitioners in the EU is estimated to reach 500,000 in 2015 and 900,000 in 2020 [13]. This fact and economic calculations will intensify the pressure on companies to additionally outsource portions of their computing tasks to lower-income countries. On the losing side will be the jobs in the still remaining islands of routine work in accounting, laboratory analysis and manufacturing. The laidoff will be doomed to join the numerous currently unemployed. They will have the difficult task to search for jobs under the conditions of a slow and jobless growth in Europe. One may expect various forms and intensity of social exclusion and destructive individualization in asocial behavior among the long-term unemployed [14: 7-8].

The conditions for employment are changing too. A lot of the available or newly created jobs have been already transformed into fixed-term or part-time precarious jobs. The experience of the global crises and the national debt crises and austerity measures has shown that managers and highly qualified workers can also easily slide to precarious jobs which interrupt their individualization process in employment. The turn to project-like employment might foster individualization in times of economic boom. In recession times or under slow economic growth, this type of flexibility in employment is a source of insecurity hindering constructive individualization.

In organizational terms, the routine of mass production will be increasingly replaced by flexible teamwork organization of production and services [24]. In parallel, the hierarchical organization of work will be less and less appropriate. Flat organizational structures with higher requirements for autonomous initiative, decision-making and responsibility of individual employees will become more and more relevant. This organizational and occupational change will continue to affect millions of employed and unemployed people in Europe. Since the beginning of the industrial revolution, each major technological and organizational change has brought about job destructions first before contributing to the creation of new jobs of better quality some time later. Thus, the disturbed individualization due to technological rationalization will be most probably followed by an increase of the options for individualization in employment. The new options will be related to new requirements for a higher level of education and training as condition for employment indeed and particularly for high-quality employment. The de-standardization of production and services will require occupational flexibilization. The share of fixed-term contracts and parttime work will most probably increase. This change will be accompanied by a negative individualization of wages and salaries as well as by other forms of deviation from the social rights and guarantees well protected in the present-day European welfare states. Most affected will be the vulnerable groups of young people with a low level of experience in employment, disabled people, women after maternity leave, representatives of ethnic minorities and immigrants.

Besides these very probable effects of the new technological breakthroughs on individualization in employment, there will be some other effects which may be no less important but cannot be precisely prognosticated now. The design and instalment of manufacturing and services based on the new ICTs is usually organized as a task on a project basis. The resolution of this task requires concentration of qualified labour for limited periods of time. The maintenance of already functioning digitalized production and services is much less labour intensive. Thus, the very nature of the ongoing reindustrialization will foster the flexibilization of work contracts by a rising share of temporary contracts and by making the contracts with free-lancing ICT professionals relatively widespread. Triangular labour contracts between the employer searching for temporary employees, a mediating labour agency and the person to be temporarily employed will certainly increase in number and relevance. One cannot expect a strengthening of unionization under these conditions. The challenges of the economic crisis made it clear that collective action can be very much needed for protecting the interests of the individualized semi-independent employed or selfemployed. However, given their labour relations, a collective action organized by them for protecting their own interests can only take place under very difficult organizational conditions, if indeed [8].

Rarely mentioned remains another tendency which is accompanying the more and more intensive use of ICTs in production and services. The new new technologies make the very precise surveillance at the workplace possible. All details of the behavior of the employees, their ICT-based social networking including, can and will be most probably closely monitored. This development undermines their autonomy and privacy as a condition for full-scale individualization. If not legally well regulated and closely monitored by independent institutions, the increasing opportunities for big data processing will open to the employer easy access to personal data with implications for the individualization of 
the employees in their occupational careers. In this context, the possibility for infringements of human rights by using most sophisticated ICT is quite realistic. This development requires discussions and actions focusing on the reduction of possibilities for hindering the individualization in the realm of employment. As seen from the opposite point of view, a lot of support to constructive individualization is expected from the fast spread of teleworking [39]. The segment of the labour force profiting from this new model of semi-independent employment is expanding fast and is expected to continue doing so. Positive effects on individualization might come about with the implementation of ICT-supported strategies and practices of human resources management fostering adaptivity to change, the motivation for life-long learning or cultural tolerance at the workplace [20].

The coming technological developments will require tremendous investments. Undoubtedly, many companies and states in Europe as well as the European Union itself have large economic resources and will try to efficiently use them for resolving the tasks of the development and use of the new digital new technologies. However, the international competition in the field is fierce and its recent outcomes are not particularly flattering for the Europeans. The number of Patent Cooperation Treaty (PCT) patent applications by country is a reliable indicator for the present-day situation in R\&D. In 2013, the USA remained the leader in PCT patent applications with 57,239 applications. The second and the third position are occupied by Japan and China with 43,918 and 21,516 applications, respectively. Germany and France are ranked on the fourth and sixth place with 17,927 and 7,899 applications [43]. It is practically impossible to draw conclusions about the future economic prosperity in each of these countries from the data. However, the development after the beginning of the industrial revolution has confirmed the link of determination between the advancement in technological innovation and the quality of employment, economic prosperity and the advancement of individualization. The industrial revolution and the accelerated individualization started in Europe, but despite the efforts of the European Union, Europe is less and less leading in the global advancement in technological innovations. Currently, the countries from East Asia are the ones fastest moving forward in the area of R\&D. This is a serious source of concerns about the future of individualization in Europe if regarded in global comparisons.

The European Union is the major economic and political factor supporting the advancement in individualization by fostering the improvement of the conditions and prospects for employment in Europe. After the failure of the EU Lisbon strategy (2000) which announced the ambitious task of transforming the EU into the leading world power in R\&D till 2010, a new strategy "For a European Industrial Renaissance" was announced at the beginning of 2014 [12]. The document is very much needed since it summarizes the sobering lessons from the global financial and economic crisis after 2008. The crisis made manifest the lacking ability of the EU to efficiently adapt to rapidly changing environments as well as the decline and slow revival of the GDP of the EU member states and, particularly, the slow revival of their industrial production.

The conclusion is that a full-scale use should be made of the current trends of "the convergence of information and communication technologies with energy and logistics networks" in order to open "new opportunities and challenges for industry" $[12,4]$. For that purpose, digitalized networks should be developed and used for connecting energy, transportation and communications in the European Union. The networks are expected to facilitate the global competitiveness of the Union and create jobs. The crucial point in these efforts is the focus of the re-industrialization of the economy of the European Union on high value-added products. Only this type of products may secure the global competitiveness of European states and the European Union. The implication is that the measures for the regulation of the economy, for the monitoring of the industrial production and for the marketing of industrial products should stimulate exactly the production and marketing of products with high value-added. This can only be achieved by strengthening the knowledge base of the European economy. Consequently, the requirement for $3 \%$ of the GDP of the EU member states to be re-invested into R\&D is repeated and stressed once more. On the part of the EU itself, the efforts to strengthen the knowledge-based economy will be facilitated by investing EUR 80 billion only through the channel of the Horizon 2020 programme. The generous funding will be basically used for research and development but also for supporting the public-private partnerships in industrial innovations. Additional EUR 100 billion will finance the European Structural and Investment Funds for supporting projects on smart industrial specialization of regions.

These institutional projects bear the promise of a plethora of options for constructive individualization supporting the institutional developments in the European Union. So it is understandable why the future of individualization takes its proper place in the strategic document on the future of the Union [13: 15-16]. The keyword is "upgrading of skills" since the mismatch of education and skills, on the one side, and the requirements of a knowledge-based innovative economy, on the other, is currently common knowledge. The suggestions of the Commission for the improvement of the educational systems, for apprenticeship training, for the crossborder enrichment of knowledge and skills are very much promising. The measures will be implemented in the future since segments of the young labour force are not educated and not properly vocationally trained in order to manage the challenges of the digitalized and knowledge-based economy in their employment. Part of the European labour force is not motivated, indeed, to manage the challenges of the innovative, 
digitalized, and knowledge-based economy. Some young people in the EU member states prefer enjoying the support of the welfare state to investing time and energy in education and vocational training in order to efficiently participate in the fierce competition for high-quality jobs. Whatever the precise share of these young people, their very existence in EU countries is indicative of the potentials of future destructive individualization manifested in criminal or in generally asocial activities.

The background issue in this context concerns the patterns in the value-normative system corresponding or not corresponding to the strategy of re-industrialization to be implemented with the support of digitalized production and services. The culture of a truly innovative society is the culture of efforts and endurance, the ethics is the ethics of responsibility. Looking carefully at the present-day culture of young people who will have to build up the future of Europe, we may have some reservations about their readiness for efforts, endurance, sacrifices in order to develop their own individualization together with the development of the common good of European societies [35: 72-95].

Some of the reasons for these doubts are related to the quality of governance in European societies and of the supranational organization of the European Union.

\section{Individualization in the governance}

The most widespread understanding of the link between individualization and governance is related to the availability of fast and reliable electronic services to citizens. In the administrative language of the European Union this understanding is presented as a strategy for the introduction and maintenance of electronic government in the EU member states. Digitalized government is faster, more flexible, could be individualized, saves labour, paper, travelling, time for waiting, and is more efficient in terms of organizational rationalization. A wellorganized system of electronic government makes the range and the content of the available public services more transparent and accessible to citizens than the traditional way of public servicing [11]. Substantial funding and organizational resources were invested in the implementation of the strategy for building and maintaining electronic government. The efforts to rationalize the administration will continue on the basis of the further developments of ICT. In the foreseeable time perspective of 2030 , the trend will be towards the strengthening of the interaction between the state institutions and the citizens. The interaction will include an increasing supply of the information required by citizen from state institutions as well as individualized information services offered to citizens.

One of the key technological and organizational issues of the electronic government concerns the stability and security of the information system. There are well-known cases of blocking the whole system of electronic government due to the activities of hackers (Estonia) or due to failures of the hardware or software. Together with the increasing complexity of the electronic systems, the security issues of egovernment are expected to remain among the central issues in the future development of electronic government. Another serious problem concerns the real or potential isolation of the less educated, disabled and pure citizens from the access to the increasingly complex and complicated services of electronic government, particularly from the access to its interactive part. Moreover, portions of important information might not be made publicly accessible or may be made accessible only for a short period of time. Public control on such policies is difficult or practically impossible.

Whatever the technological or social precautions, it is clear that in most cases the achievements in the development of electronic government serve the needs of the vast majority of citizens. The relevant future outcome of the measures for developing electronic government will be related to the real inclusion of citizens in the preparation and the implementation of the state policies as well as to the control of their efficiency. This is a very promising prospect for a shift in the philosophy of the development and functioning of the electronic government. With many variations from one European country to another, the strategy, so far, mostly aims at developing a technocratic electronic government and not democratic electronic governance. The linking of both will be a task for technological inventions and the political empowerment of people in the long run [30]. It is the prospect for strengthening the democratic political mechanisms which still remains less debated. The applications include the use of digitalized information and new information technologies for the interactive participation of citizens in the political discussions and decision-making, for democratic political mobilization as well as for more sophisticated mechanisms of accountability of politicians and administrators. Various options for using information technologies for these purposes are still in the period of testing in the mobilization of mass movements and in the relevance of their outcomes [37]. It is clear that the new new technologies will immensely differentiate and enlarge the social spaces for autonomous orientation, decision and action of individuals in the area of public governance. As seen from the point of view of the action dimension of individualization, the prospects for strengthening the knowledge and the technological basis of the autonomous orientation, decision and action of individuals in the operation with data are rather important too [26].

This is a message which comes in times of declining public interest in the political process as it was known in the twentieth century. Particularly young people in European societies tend to increasingly understand and practice individualization as distancing themselves from the collective concerns and 
collective action serving the production, improvement and defense of the societal common good. The believe is widespread that improvements of the economic, political and cultural situation in the European societies could be hardly achieved by organized collective action but - if indeed - by the aggregation of the results of individual efforts to improve personal situations. This point of view has been strengthened by the long predominance of neo-liberal ideas stressing the atomization of economic and political life. Al Gore put a smashing diagnosis on the outcomes of the ideology of neoliberalism and of the related policies as "... degradation of democracy in the United States and ... disfunctionality of governance in the world community ..." [18: XV]. Being confronted with the destructive individualization of atomistic neo-liberalism, some politics and political parties in Europe turn back to the best known and historically rather compromised mechanism of societal integration by fostering collectivist nationalism. The first result is the policy of disrupting the constructive individualization of the representatives of ethnic, religious and political minorities. The second result is the poisoning of international relations with the side effects of policies undermining the institutional framework of constructive individualization.

Against this background, the new developments in the ICTmediated participation in political processes seem to counter the trend of self-isolation from politics in one way or another. In the already long-lasting peaceful times marked by the predominance of the welfare state in Europe, the use of the internet is practically the only means for efficiently involving people, and particularly young people, in the political information exchange, debates, collectively prepared decisions for action and in the political action itself. All of these elements of political mobilization are inherent in the authentic democratic political governance at various social structural levels from small groups to settlements, national regions, states, macroregions and the structural level of the global society.

The issues of employment can be discussed as political issues of common interest. The efforts to resolve them might be developed at all mentioned social structural levels [7]. The internet is particularly useful for this purpose since it offers support to the interested individuals along the whole action chain. Due to the easy access to information sources, the internet makes possible the intensive knowledge collection. Comparing the information content of various sources the interested individual may check and compare the information items. In the course of checking information items, the individual may develop suspicion to some of them and trust to others when trying to establish his/her own opinion on the issues under scrutiny. The process of individualization might stop at the point of opinion-making or might also continue towards developing a personal strategy for action. It might include decisions for information sharing, building collective opinion or efforts to prepare and implement personal or collective practical activity. The decision might be materialized in actions of political participation of different types or not. Depending on the circumstances, the involvement of individuals in the whole chain of political activities might intensify or not in the future. Some of the circumstances are related to the use of the ICT-supported social media.

The most visible new forms of ICT-mediated political participation are currently related to Twitter and Facebook social networks. Their potentials for social networking and political mobilization are recognizable from the numbers of their users. In December 2012, some 251 million of the European population used Facebook [23]. The tendency is that this type of involvement in the discussions on public good and in actions for producing, improving and defending it is getting increasingly intensive. Millions of mostly young Europeans are already accustomed to sharing experience and concerns about social issues, or directly to appealing for change of social situations by using social media. ICT-supported social networks were recently widely used for political mobilization against austerity measures in Greece, Portugal and Spain. This type of information exchange and political mobilization might develop into an incorporation of the Enlightenment's dream for the civil society as mediator between the private sphere, the market and the state in the future. The civil society might be also the promising mechanism for the fast and efficient accountability of politicians to their electorate [9]. However, in many cases, the messages disseminated by means of Twitter or Facebook are too personal, chaotic or of hardly any practical relevance. Nevertheless, it might be taken for granted that social media will be used more often and more efficiently in the future European political life [1].

The potentials of the electronic social media have been timely recognized by European politicians too. Most of them are active in their efforts to reach public understanding for their platforms and support for their politics via the social media. This type of communication of political messages which provoke or facilitate political mobilization is widespread and tends to become crucially important for politicians. Will their electronically mediated daily work help them to make political life more transparent and attractive for broader political participation? Will the electronically mediated politics efficiently support direct democracy? Will the wide use of electronic media in everyday politics help to restore the very much undermined trust in European politicians and politics or will it strengthen the feelings of alienation from political life? These issues will have to be clarified in the course of the coming decades. At this point of time, one may expect future diversification and broader use of electronic channels for political communication and mobilization. So far, it is only visible that some minorities in politics successfully made their voice heard via the electronic social networks. Some new parties of the "pirates" type could raise political support by intensively using the digital social media. 
The cautious predictions about the future relevance of ICT in the European political life should take into account the digital divide between as well as in European societies. The specifics of the local political traditions should be taken into account in the prognostications too [40]. Another direction of cautious predictions concerns the trends towards the strengthening of the supranational macro-regional governance in the form of the ASEAN, MERCOSUR, NAFTA, and particularly in the form of the European Union [34]. The emerging new patterns of individualization in the European Union will have implications of continental and global governance. When approaching 2030, global governance will become more diffuse, multipolar, interconnected, fragile and difficult to predict. Vice versa, the major characteristics of the developments at the level of global and macro-regional interactions [19] will be the unstable institutional framework of the continuous individualization in Europe.

\section{Conclusions}

Europe and the global society are involved in a fast transition from the Gutenberg to the internet era. The experience which has been accumulated in the transition leads to the conclusion that the global society and the supranational continental organizations are not moving towards the end of the conflictual history of humankind. One of the reasons for this strong deviation from the predictions of Francis Fukuyama is the controversial character of the global trend of individualization. It is among the major moving forces of the present-day liberation of individuals, groups and societies from the constraints of traditionalism. At the same time, individualization provokes and reproduces tensions and conflicts due to the weakening of the mechanisms of social and societal integration.

Under these global conditions, the future of individualization will be basically determined by four factors. The above analysis has made it clear that the major areas, the speed and the outcomes of individualization will be very much influenced by the development of technologies in general and of the information and communications technologies in particular. The economic growth and the economic distributions will be quite important for the future of individualization which has been and will be connected to the rise and the prosperity of the middle class. There might be various political decisions and actions fostering or hindering individualization. The culture may foster mutual understanding and tolerance which are needed for widespread individualization or may hinder it.

Due to the volatility of these determining factors, individualization will most probably be marked by uneven developments from one action area to another action area and from country to country. Therefore, the local management of the constructive and destructive manifestations of the global trend of individualization in Europe will require high levels of concentration, imagination and endurance.

Open Access This article is distributed under the terms of the Creative Commons Attribution License which permits any use, distribution, and reproduction in any medium, provided the original author(s) and the source are credited.

\section{References}

1. Akrivopoulou C, Garipidis N (eds) (2013) Digital democracy and the impact of technology on governance and politics: new globalized practices. Information Science Reference, Hershey

2. Atkinson W (2010) Class, individualization, and late modernity: in search of the reflexive worker. Palgrave Macmillan, Basingstoke

3. Bauman Z (2001) The individualized society. Polity Press, Cambridge

4. Beck U, Beck-Gernsheim E (2002) Individualization: institutionalized individualism and its social and political consequences. Sage, London

5. de Beer P, Koster F (2009) Sticking together or falling apart? Solidarity in an Era of individualization and globalization. Amsterdam University Press, Amsterdam

6. Berger PA, Hitzler R (eds) (2010) Individualisierungen. Ein Vierteljahrhundert „Jenseits von Stand und Klasse“? Verlag für Sozialwissenschaften, Wiesbaden

7. Blanpain R, Auvergnon P (2009) Employment policies and multilevel governance. Kluwer Law International, Alphen Aan Den Rijn

8. Bouchareb R (2010) 'Growing Power Asymmetries, Individualization and the Continuing Relevance of Collective Responses'. In: Thornley C, Jefferys S, Appay B (eds) Globalization and precarious forms of production and employment. Challenges for workers and unions. Edward Elgar, Cheltenham, pp 199-213

9. Castells M (2012) Networks of outrage and hope: social movements in the internet age. Polity Press, Cambridge

10. Dawson M (2013) Late modernity, individualization and socialism: an associational critique of neoliberalism. Palgrave Macmillan, Basingstoke

11. European Commission (2010) The European eGovernment action plan 2011-2015. Harnessing ICT to promote smart, sustainable \& innovative Government. EC, COM, Brussels, (2010) 743 final

12. European Commission (2014a) For a European industrial renaissance. EC, COM, Brussels, (2014) 14 final

13. European Commission (2014b) e-Skills for Jobs in Europe. Measuring Progress and Moving ahead. European Commission, Brussels

14. Foundation Focus (2012) The Future of Europe's Labour Market. N 12, December.

15. Genov N (2012) The Challenge of Four Global Trends'. In: Genov N (ed) Global trends and regional development. Routledge, New York, pp $1-24$

16. Genov, Nikolai (2014) 'Challenges of Individualization'. International Social Science Journal, Vol. 64, issue 212-213 (forthcoming).

17. Giddens A (1991) Modernity and self-identity: self and society in the late modern age. Polity Press, Cambridge

18. Gore A (2013) The Future. WH Allen, London

19. Grevi G, Keohane D, Lee B, Lewis P (2013) Empowering Europe's future: governance, power and options for the EU in a changing world. European Commission, Brussels 
20. Holtgrewe U (2014) 'New New Technologies: The Future and the Present of Work in Information and Communication Technology'. New Technology Work and Employment 29(1):9-24

21. Honneth A (2004) Organized Self-Realization: Some Paradoxes of Individualization'. Eur J Soc Theory 7(4):463-478

22. Howard C (ed) (2007) Contested individualization: debates about contemporary personhood. Palgrave Macmillan, New York

23. Internet World Stats (2014) http://www.internetworldstats.com/ stats4.htm (16 July, 2014).

24. Kirn S (2008) Individualization engineering. Gestaltung adaptiver Wertschöpfungssysteme für individualisierte Sachgüter und Dienstleistungen. Cuvillier Verlag, Göttingen

25. Marsh P (2012) The new industrial revolution: consumers, globalization and the end of mass production. Yale University Press, New Haven

26. McLoughlin I, Wilson R, Martin M (2013) Digital government at work: a social informatics perspective. Oxford University Press, Oxford

27. Morello D, Burton B (2006) Future worker 2015: extreme individualization. Gardner, Stamford

28. Nevitte N, Cochrane C (2007) Individualization in Europe and in America. In: Esmer Y (ed) Measuring and mapping cultures. Brill, Leiden, pp 99-126

29. NIC, 2012. Global Trends 2030: Alternative Worlds (2012) Washington, DC: National Intelligence Council, available at http://globaltrends2030.files.wordpress.com/2012/11/globaltrends-2030-november2012.pdf. Accessed 14 June 2014

30. Nixon PG (ed) (2010) E-government in Europe: re-booting the state. Routledge, London
31. Osserwaarde M (2013) Theorizing European societies. Palgrave Macmillan, Basingstoke

32. Perlow LA, Kelly EL (2014) 'Toward a Model of Work Redesign for Better Work and Better Life'. Work Occup 41:111-134

33. Rifkin J (2011) The third industrial revolution: how lateral power is transforming energy, the economy, and the world. Palgrave Macmillan, New York

34. Rifkin J (2013) The european dream: how Europe's vision of the future is quietly eclipsing the American dream. Wiley, Oxford

35. Roberts K (2009) Youth in transition: Eastern Europe and the West. Palgrave Macmillan, Basingstoke

36. Søren J (2013) Solidarity in individualized societies: recognition, justice and good judgement. Taylor and Francis, Hoboken

37. van Stekelenburg J et al (eds) (2013) The future of social movement research. University of Minnesota Press, Minneapolis

38. Therborn G (2013) The killing fields of Inequality. Polity Press, Cambridge

39. Tony S (2014) Teleworking and its effectiveness on work-life balance. GRIN Verlag, Munich

40. Tsatsou P (2011) Digital divides in Europe: culture, politics and the Western-Southern Divide. P. Lang, Oxford

41. United Nations Development Programme (2014) Human development report. UNDP, New York

42. Westkämper E (2014) Towards the Re-Industrialization of Europe. Concept for Manufacturing for 2030. Springer, Berlin

43. WIPO (2014) Who Filed the Most PCT Patent Applications in 2013 ? WIPO, Geneva 